\title{
cmaJOPEN
}

\section{Cannabis-related emergency department visits by youths and their outcomes in Ontario: a trend analysis}

\author{
Melanie Bechard MD, Paula Cloutier MA, Isac Lima PhD, Mina Salamatmanesh MS, Roger Zemek MD, \\ Maala Bhatt MD MSc, Sinthuja Suntharalingam MD, Paul Kurdyak MD PhD, Melissa Baker PhD, \\ William Gardner PhD
}

\section{Abstract}

Background: Cannabis-related emergency department visits can be an entry point for youths to mental health and substance use care systems. We aimed to examine trends in cannabis-related emergency department visits as a function of youths' age and sex.

\begin{abstract}
Methods: Using administrative data, we examined all visits to emergency departments in Ontario, Canada, from 2003 to 2017 , by youth aged 10-24 years (grouped as 10-13, 14-18 and 19-24 yr) to determine trends in cannabis-related emergency department visits. Cannabis-related visits were identified using International Statistical Classification of Diseases and Related Health Problems, 10th Revision codes for cannabis poisoning and mental disorders due to cannabinoids. We categorized presentations as "less severe" versus "more severe" using scores assigned by nurses at triage.
\end{abstract}

Results: We examined 14697778 emergency department visits. Cannabis-related visits increased from 3.8 per 10000 youths (95\% confidence interval [Cl] 3.5-4.0) in 2003 to 17.9 (95\% Cl 17.4-18.4) in 2017, a 4.8-fold increase (95\% Cl 4.4-5.1). Rates increased for both sexes and each age group. Males were more likely to have a visit than females (rate ratios $\geq 1.5$ in 2003 and 2017 ). The number of cannabis-related visits in 2017 was 25.0 per 10000 (95\% Cl 24.0-25.9) among youth aged 19-24 years, 21.9 per 10000 (95\% Cl 20.9-22.9) among those aged 14-18 years, and 0.8 per 10000 (95\% Cl 0.5-1.0) among those aged 10-13 years. In 2017, 88.2\% (95\% Cl $87.3 \%-89.0 \%)$ of cannabis-related visits and $58.1 \%(95 \% \mathrm{Cl} 58.0 \%-58.2 \%)$ of non-cannabis-related visits were triaged as "more severe," (rate ratio 1.52, 95\% Cl 1.50-1.53). Similarly, in 2017, 19.0\% (95\% Cl 18.0\%-20.1\%) of cannabis-related visits and $5.8 \%(95 \% \mathrm{Cl} 5.7 \%-5.8 \%)$ of non-cannabis-related visits resulted in hospital admission (rate ratio 3.3, 95\% Cl 3.1-3.5).

Interpretation: Rates of cannabis-related emergency department visit by youths aged 10-24 years increased almost fivefold from 2003 to 2017, with increases in visit severity and hospital admissions. These trends describe an emerging public health problem, and research is needed to identify the causes of this increase and the health and social consequences of cannabis-related visits for these youths.

annabis use can have chronic and acute health consequences resulting in the use of hospital emergency services. Patients may present to the emergency department with agitation, psychosis, anxiety or emesis after cannabis use. ${ }^{1,2}$ Younger children seen in the emergency department after ingestion of cannabis may present with unexplained lethargy, ataxia, tachycardia, mydriasis or hypotonia., Cannabis exposure in children may require intubation or admission to the intensive care unit. ${ }^{3}$ Cannabis exposure, particularly in youth under 18 years, is also associated with an increased risk of psychosis and long-term cognitive problems. ${ }^{5,6}$

The nonspecific presenting symptoms of cannabis use can pose a diagnostic challenge for emergency department physicians, particularly if the patient does not disclose recent cannabis use or if ingestion was unknown to the child's caregivers or bystanders. Such patients may undergo costly diagnostic tests, including bloodwork, electrocardiography and neuroimaging. ${ }^{7}$ By quantifying the trends of cannabis-related visits, physicians can be furnished with information to encourage maintenance of a high index of suspicion for cannabis use, which may result in improved management of cannabisrelated emergency department visits among youths. The emergency department is also an important entry point for youths to the mental health and substance use care systems, so understanding trends in cannabis-related emergency department visits is important for health system planning and the organization of connected care systems.

Therefore, the objectives of our study were to present annual rates of cannabis-related emergency department visits, and the severity of such visits, among youths aged 10-24 years

\section{Competing interests: None declared.}

This article has been peer reviewed.

Correspondence to: William Gardner, wgardner@cheo.on.ca

CMAJ Open 2022 February 8. DOI:10.9778/cmajo.20210142 
in Ontario from 2003 to 2017. We studied these trends as a function of youths' age and sex because these differences in drug use are well established., 8

\section{Methods}

\section{Study design, setting and participants}

This study is an analysis of trends in routinely collected data. We examined all visits to Ontario emergency departments from 2003 to 2017 by youth aged 10-24 years with an Ontario Health Insurance Plan number. This period was chosen to align with our previous study of trends in emergency department visits for mental health and self-harm. ${ }^{10}$ This age range captures the highest-risk groups for cannabis-related emergency department visits. ${ }^{11,12}$

\section{Data sources}

Data on emergency department visits were obtained from the Canadian National Ambulatory Care Reporting System (NACRS). The variables collected from the NACRS database included International Statistical Classification of Diseases and Related Health Problems, 10th Revision (ICD-10) diagnostic codes, ${ }^{13}$ Canadian Triage and Acuity Scale (CTAS) scores, ${ }^{14-16}$ year of emergency department presentation, sex and age. The Registered Persons Database was used to link emergency department youth records with rural status and neighbourhood income quintile. The Ontario population counts by year, age and sex were obtained from population estimates by Statistics Canada held by the Ontario Ministry of Health and were linked using encoded identifiers at ICES.

\section{Measurements}

\section{Cannabis-related visits}

Cannabis-related visits were identified using ICD-10 codes T407 "(Poisoning by narcotics and psychodysleptics [hallucinogens]: cannabis [derivatives])"17 and F12 "(Mental and behavioural disorders due to use of cannabinoids)." 18 ICD-10 codes have not been validated for cannabis-related emergency department visits. However, studies of opioid poisoning in routinely collected health records ${ }^{19}$ and alcohol intoxication in emergency department records ${ }^{20}$ suggest that these codes have moderate validity.

Gibson and colleagues ${ }^{21}$ studied the quality of NACRS data by carrying out re-abstractions of charts at several Ontario emergency departments and found agreement rates for ICD10 codes that ranged from $86 \%$ to $90 \%$. DeYoung and colleagues ${ }^{22}$ noted excellent sensitivity and specificity by using the same ICD-10 codes to identify cannabis-related emergency department visits, and several studies have used these codes to identify such visits. ${ }^{23-28}$ However, another study suggests that use of health administrative data to identify substance use presentations has low sensitivity but high specificity. ${ }^{29}$

\section{Visit severity}

Triage nurses assign a CTAS score to patients on entry to the emergency department. For clarity of presentation, we grouped the 5 CTAS levels as less severe ("nonurgent" or "less urgent") versus more severe ("urgent," "emergent" or "resuscitation"). We also recorded whether patients presenting to the emergency department were admitted to hospital.

\section{Demographic variables}

Data were gathered on patients' age, grouped as 10-13, 14-18 and 19-24 years. The age breakpoints were chosen as proxies for stages in child development, between younger and older adolescents, and older adolescents and young adults. We also gathered data on patient sex, residence in a rural census area and income quintile of the patient's census area.

\section{Statistical analysis}

To describe changes in emergency department visits, we calculated the rates of cannabis-related visits per 10000 emergency department visits in 2003 and 2017. Some youths had more than 1 cannabis-related visit in a year. To eliminate the clustering of visits among youths, our primary analyses examined counts of youths with at least 1 cannabis-related visit in a year. We divided these counts by the Ontario youth population during each year ${ }^{30}$ to report rates of youths with at least 1 cannabisrelated visit per 10000 youths. We plotted these rates from 2003 to 2017 with loess-smoothed curves with $95 \%$ confidence intervals (CIs). We conducted a Poisson regression analysis of trends in the rates of youths with cannabis-related visits to the emergency department, and to determine how those trends varied by age and sex (description of statistical methods is available in Appendix 1, www.cmajopen.ca/content/10/1/E100/ suppl/DC1).

Rate ratios were used to capture the association between cannabis-related visits and demographic characteristics. We reported rate ratios with $95 \% \mathrm{CIs}^{31}$ and, given our large sample size, omitted significance tests. Statistics were calculated using R Version 4.0.3.

\section{Ethics approval}

The Research Ethics Board of the Children's Hospital of Eastern Ontario approved this study.

\section{Results}

A total of 14697778 emergency department visits by eligible patients occurred between 2003 and 2017. Table 1 reports the demographic characteristics of patients and counts of cannabisrelated emergency department visits in 2003 and 2017.

\section{Rates of cannabis-related visits}

Cannabis-related emergency department visits increased between 2003 and 2017 for both sexes and all age groups (Table 1). Among patients aged 10-24 years, cannabis-related visits increased from 11.0 (95\% CI 10.3-11.7) to 51.7 (95\% CI 50.3-53.1) visits per 10000 emergency department visits, a 4.7-fold increase (95\% CI 4.4-5.0).

In 2017, rates of cannabis-related visits were higher among males (69.7 visits/10000 visits, $95 \%$ CI $67.3-72.1)$ than females (36.6 visits/10000 visits, 95\% CI 35.0-38.2; rate ratio 1.9, 95\% CI 1.8-2.0). Rates were higher among youths aged 19-24 years 


\begin{tabular}{|c|c|c|c|c|c|c|c|c|c|}
\hline \multirow[b]{2}{*}{ Variable } & \multicolumn{4}{|c|}{2003} & \multicolumn{4}{|c|}{2017} & \multirow[b]{2}{*}{$\begin{array}{c}\text { Increase } \\
2003-2017 \ddagger \\
(95 \% \mathrm{Cl})\end{array}$} \\
\hline & $\begin{array}{l}\text { Non- } \\
\text { cannabis- } \\
\text { related } \\
\text { visits }\end{array}$ & $\begin{array}{c}\text { Cannabis- } \\
\text { related } \\
\text { visits }\end{array}$ & $\begin{array}{l}\text { Cannabis- } \\
\text { related } \\
\text { visits } / 10000 \\
\text { ED visits* } \\
(95 \% \mathrm{Cl})\end{array}$ & $\begin{array}{c}\text { Rate ratio } \\
(95 \% \mathrm{Cl})\end{array}$ & $\begin{array}{l}\text { Non- } \\
\text { cannabis- } \\
\text { related } \\
\text { visits }\end{array}$ & $\begin{array}{l}\text { Cannabis- } \\
\text { related } \\
\text { visits }\end{array}$ & $\begin{array}{l}\text { Cannabis- } \\
\text { related } \\
\text { visits } / 10000 \\
\text { ED visits* } \\
(95 \% \mathrm{Cl})\end{array}$ & $\begin{array}{c}\text { Rate ratio† } \\
(95 \% \mathrm{Cl})\end{array}$ & \\
\hline All visits & 900256 & 992 & $\begin{array}{c}11.0 \\
(10.3-11.7)\end{array}$ & - & 1004909 & 5224 & $\begin{array}{c}51.7 \\
(50.3-53.1)\end{array}$ & - & $\begin{array}{c}4.7 \\
(4.4-5.0)\end{array}$ \\
\hline \multicolumn{10}{|l|}{ Sex } \\
\hline Male & 449828 & 650 & $\begin{array}{c}14.4 \\
(13.3-15.5)\end{array}$ & $\begin{array}{c}1.9 \\
(1.7-2.2)\end{array}$ & 458291 & 3215 & $\begin{array}{c}69.7 \\
(67.3-72.1)\end{array}$ & $\begin{array}{c}1.9 \\
(1.8-2.0)\end{array}$ & $\begin{array}{c}4.8 \\
(4.4-5.3)\end{array}$ \\
\hline $\begin{array}{l}\text { Female } \\
\text { (Ref.) }\end{array}$ & 450428 & 342 & $\begin{array}{c}7.6 \\
(6.8-8.4)\end{array}$ & - & 546618 & 2009 & $\begin{array}{c}36.6 \\
(35.0-38.2)\end{array}$ & - & $\begin{array}{c}4.8 \\
(4.3-5.4)\end{array}$ \\
\hline $14-18$ & 308047 & 511 & $\begin{array}{c}16.6 \\
(15.1-18.0)\end{array}$ & $\begin{array}{c}9.9 \\
(6.9-14.1)\end{array}$ & 320522 & 1987 & $\begin{array}{c}61.6 \\
(58.9-64.3)\end{array}$ & $\begin{array}{c}22.9 \\
(17.3-30.2)\end{array}$ & $\begin{array}{c}3.7 \\
(3.4-4.1)\end{array}$ \\
\hline $\begin{array}{l}\text { 10-13 } \\
\text { (Ref.) }\end{array}$ & 190698 & 32 & $\begin{array}{c}1.7 \\
(1.1-2.3)\end{array}$ & - & 189169 & 51 & $\begin{array}{c}2.7 \\
(2.0-3.4)\end{array}$ & - & $\begin{array}{c}1.6 \\
(1.0-2.5)\end{array}$ \\
\hline \multicolumn{10}{|c|}{ Income quintile§ } \\
\hline 1 (lowest) & 203770 & 262 & $\begin{array}{c}12.8 \\
(11.3-14.4)\end{array}$ & $\begin{array}{c}1.5 \\
(1.2-1.9)\end{array}$ & 240088 & 1395 & $\begin{array}{c}57.8 \\
(54.7-60.8)\end{array}$ & $\begin{array}{c}1.2 \\
(1.1-1.3)\end{array}$ & $\begin{array}{c}4.5 \\
(3.9-5.1)\end{array}$ \\
\hline 2 & 184854 & 219 & $\begin{array}{c}11.8 \\
(10.3-13.4)\end{array}$ & $\begin{array}{c}1.4 \\
(1.1-1.7)\end{array}$ & 197856 & 1042 & $\begin{array}{c}52.4 \\
(49.2-55.6)\end{array}$ & $\begin{array}{c}1.1 \\
(1.0-1.2)\end{array}$ & $\begin{array}{c}4.4 \\
(3.8-5.1)\end{array}$ \\
\hline 3 & 176001 & 197 & $\begin{array}{c}11.2 \\
(9.6-12.7)\end{array}$ & $\begin{array}{c}1.3 \\
(1.1-1.6)\end{array}$ & 194966 & 932 & $\begin{array}{c}47.6 \\
(44.5-50.6)\end{array}$ & $\begin{array}{c}1.0 \\
(0.9-1.1)\end{array}$ & $\begin{array}{c}4.3 \\
(3.6-5.0)\end{array}$ \\
\hline $\begin{array}{l}\text { Rural } \\
\text { (Ref.) }\end{array}$ & 230609 & 122 & $\begin{array}{c}5.3 \\
(4.3-6.2)\end{array}$ & - & 180651 & 574 & $\begin{array}{c}31.7 \\
(29.1-34.3)\end{array}$ & - & $\begin{array}{c}6.0 \\
(4.9-7.3)\end{array}$ \\
\hline \multicolumn{10}{|c|}{$\begin{array}{l}\text { Note: } \mathrm{Cl}=\text { confidence interval, ED }=\text { emergency department, Ref. }=\text { reference category. } \\
{ }^{\circ} \text { Cannabis-related visits } / 10000 \mathrm{ED} \text { visits }=10000 \times(\text { cannabis-related visits }) /(\text { non-cannabis-related visits }+ \text { cannabis-related visits). } \\
\text { †Rate ratio is the ratio of the rates of cannabis-related visits } / 10000 \text { youths by category. } \\
\text { †Increase } 2003-2017=(\text { cannabis-related visits } / 10000 \text { in } 2017) /(\text { cannabis-related visits } / 10000 \text { in 2003). } \\
\text { §Income quintile and rural status had }<1 \% \text { missing data. }\end{array}$} \\
\hline
\end{tabular}

(63.9 visits/10000 visits, 95\% CI 61.7-66.1) and youths aged $14-18$ years (61.6 visits/10000 visits, 95\% CI 58.9-64.3) than among those aged $10-13$ years (2.7 visits/10000 visits, $95 \%$ CI 2.0-3.4). The rate ratios were more than 20 -fold greater for both older groups compared with the younger age group.

Rates in 2017 were higher among youths residing in areas with the lowest income quintile (57.8 visits/10 000 visits, 95\% CI 54.7-60.8) than among those living in areas with the highest income quintile (47.3 visits/10000 visits, $95 \%$ CI 44.1-50.4) (rate ratio 1.2 , 95\% CI 1.1-1.3). Finally, youths who resided in a nonrural census area had 55.8 cannabis-related visits per 10000 emergency department visits (95\% CI 54.2-57.4), and those living in a rural area had 31.7 visits per 10000 visits (95\% CI 29.1-34.3) (rate ratio $1.8,95 \%$ CI 1.6-1.9).

Rates of youths with at least 1 cannabis-related visit Figure 1 presents the trends between 2003 and 2017 in rates of youths with at least 1 cannabis-related visit per 10000 Ontario youths. Table 2 contrasts the rates in 2003 and 2017. Figure 1A presents the rates for all youths, which increased from 3.8 youths per 10000 (95\% CI 3.5-4.0) in 2003 to 17.9 (95\% CI 17.4-18.4) in 2017 (rate ratio 4.8, 95\% CI 4.4-5.1). Rates of youths with cannabis-related visits per 10000 increased between 2003 and 2017 for both sexes (Figure 1B), each age group (Figure 1C), and each age $\times$ sex subgroup (Figure 1D). 


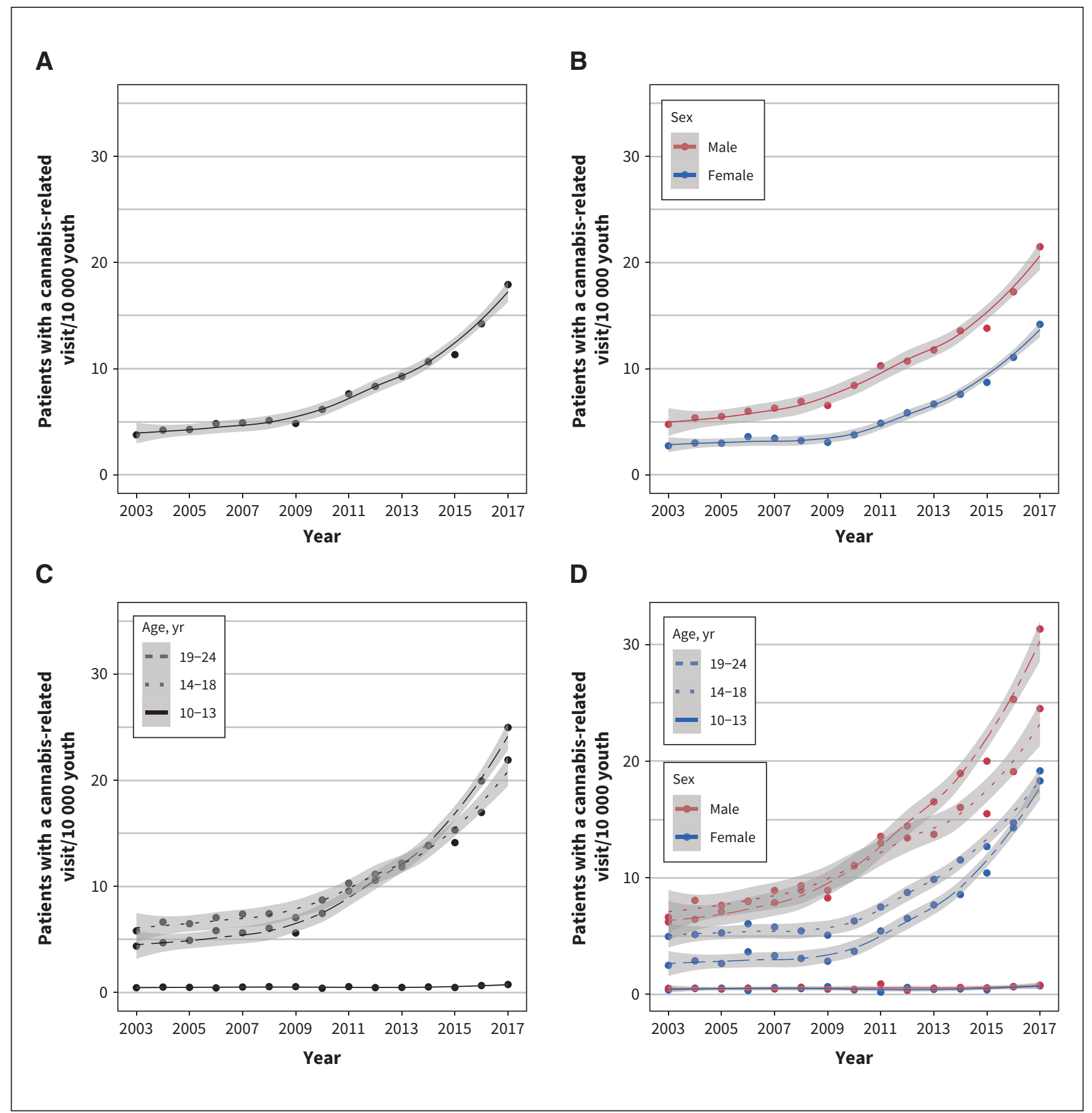

Figure 1: Trends in rates of youths with at least 1 cannabis-related emergency department visit per 10000 Ontario youths. (A) All cannabisrelated visits; (B) patients with a cannabis-related visit, by sex; (C) patients with a cannabis-related visit, by age; (D) patients with a cannabisrelated visit, by sex and age. Note: Smoothed curves with 95\% confidence bands (shaded areas) were fit to the rates using the loess method.

Males had higher rates than females throughout the time period, with rate ratios of 1.5 or greater in both 2003 and 2017.

Figure $1 \mathrm{C}$ shows increases in youths with cannabisrelated visits per 10000 between 2003 and 2017 among youths aged 19-24 years (rate ratio 5.7, 95\% CI 5.2-6.3) and youths aged 14-18 years (rate ratio 3.8, 95\% CI 3.4-4.2). The increases in the 2 older groups were nonlinear, with accelerating growth over time. In 2017, the rate was 25.0 per 10000 youths (95\% CI 24.0-25.9) for youths aged $19-24$ years, and the rate was 0.8 (95\% CI $0.5-1.0)$ for those aged 10-13 years (rate ratio 33.0, 95\% CI 24.8-43.7).

Finally, Figure 1D and Table 2 show that the sex difference in youths per 10000 occurred among the groups aged 19-24 and $14-18$ years, where the rates for males were 1.3 or more 


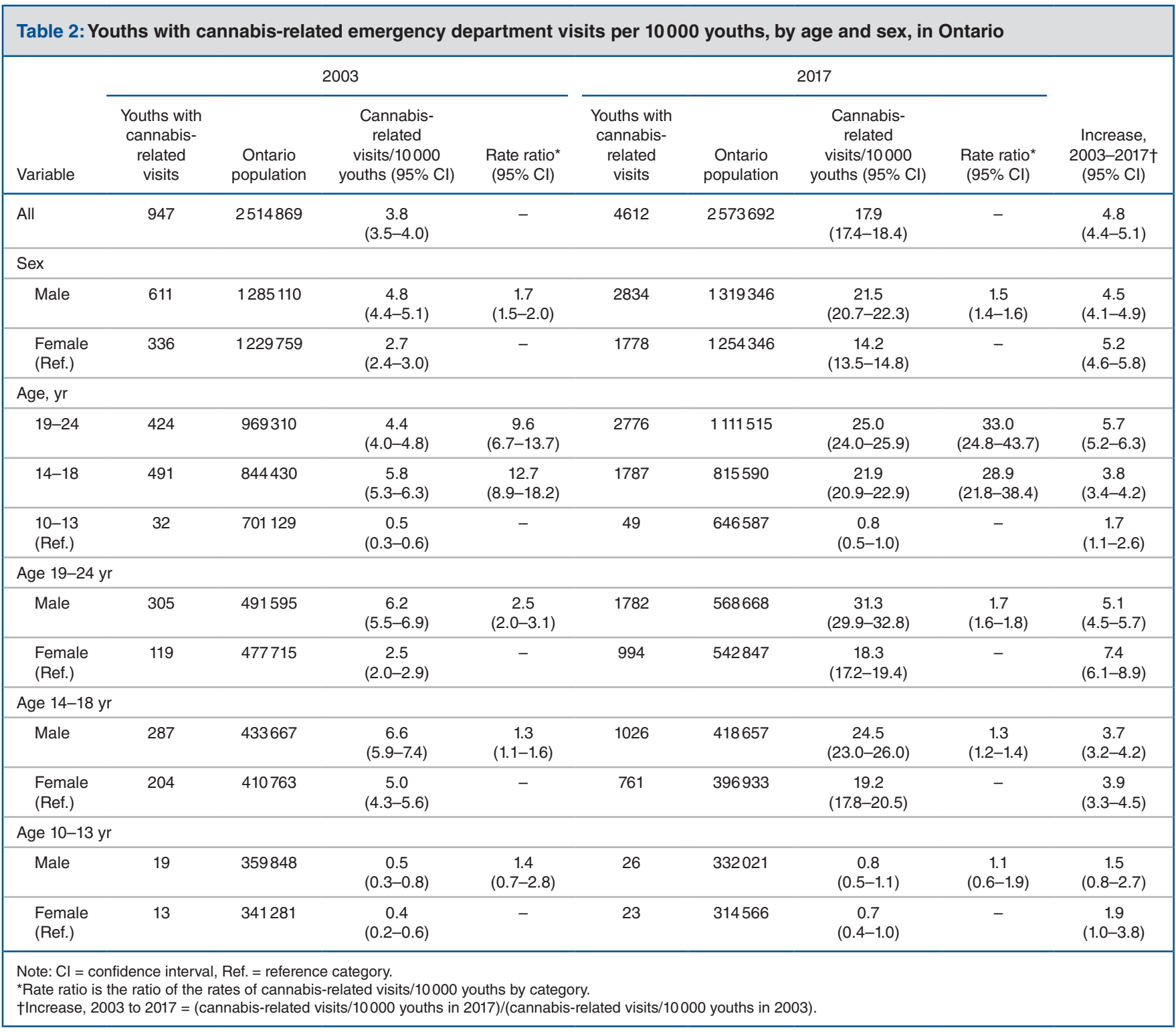

times greater than for females in 2003 and 2017. The rate ratios for males versus females among youths aged 10-13 years, however, were not statistically different from 1.0. In Appendix 1, the data presented in Figure 1 have been analyzed using Poisson regression. The results of that analysis show that, as reported above, there has been an accelerating increase in rates of youths with cannabis-related emergency department visits, with higher rates for males, and less increase for youths aged $10-13$ years.

\section{Triaged visit severity and hospital admissions}

Figure 2A shows that cannabis-related visits were more likely to be triaged as severe than non-cannabis-related visits. In 2003, $65.7 \%$ (95\% CI $62.8 \%-68.7 \%)$ of cannabis-related visits were severe, and $31.0 \%$ (95\% CI $30.9 \%-31.1 \%$ ) of non-cannabisrelated visits were severe (rate ratio 2.1 , 95\% CI 2.0-2.2) (Table 3). In 2017, 88.2\% (95\% CI 87.3\%-89.0\%) of cannabis- related visits were severe, and 58.1\% (95\% CI 58.0\%-58.2\%) of non-cannabis-related visits were severe (rate ratio $1.52,95 \%$ CI 1.50-1.53). The severity of both types of visits increased over time (rate ratio 1.3, 95\% CI 1.3-1.4, for cannabis-related and $1.9,95 \%$ CI 1.9-1.9, for non-cannabis-related visits).

Figure 2B shows that cannabis-related visits were more likely to result in hospital admissions. In 2003, 9.0\% (95\% CI $7.2 \%-10.8 \%$ ) of cannabis-related visits resulted in hospital admission, and 5.0\% (95\% CI 5.0\%-5.1\%) of non-cannabisrelated visits resulted in admission (rate ratio $1.8,95 \%$ CI $1.5-$ 2.2) (Table 3). In 2017, 19.0\% (95\% CI 18.0\%-20.1\%) of cannabis-related visits resulted in admission, and 5.8\% (95\% CI $5.7 \%-5.8 \%)$ of non-cannabis-related visits resulted in admission (rate ratio 3.3, 95\% CI 3.1-3.5). Admissions increased from 2003 to 2017 for both types of visits (rate ratio 2.1, 95\% CI 1.7-2.6, for cannabis-related and 1.2, 95\% CI 1.1-1.2, for non-cannabis-related visits). 


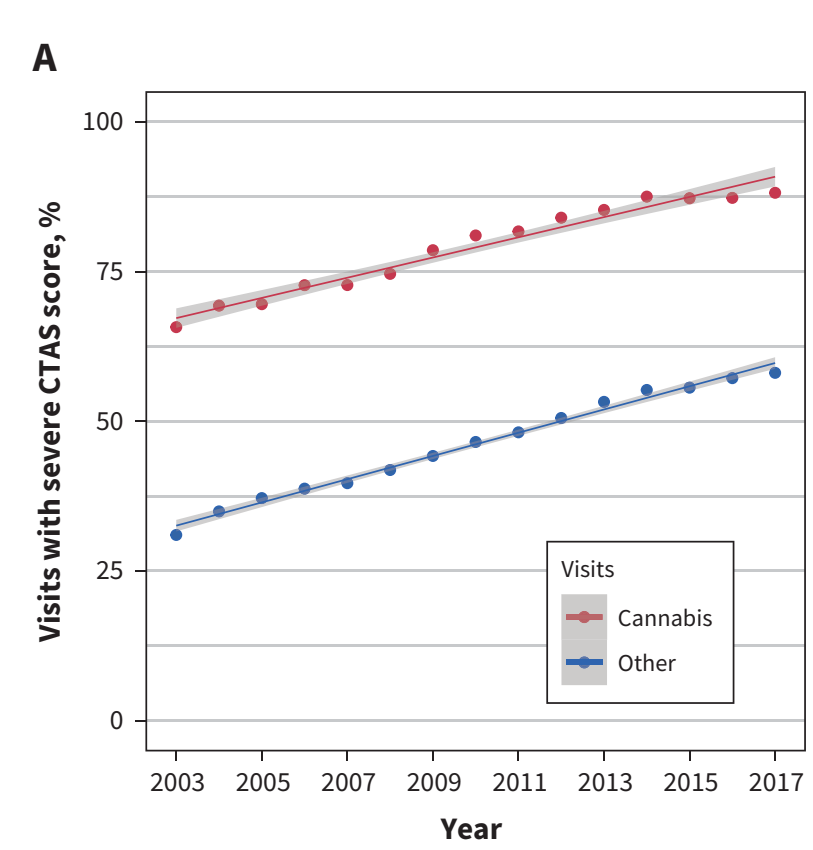

B

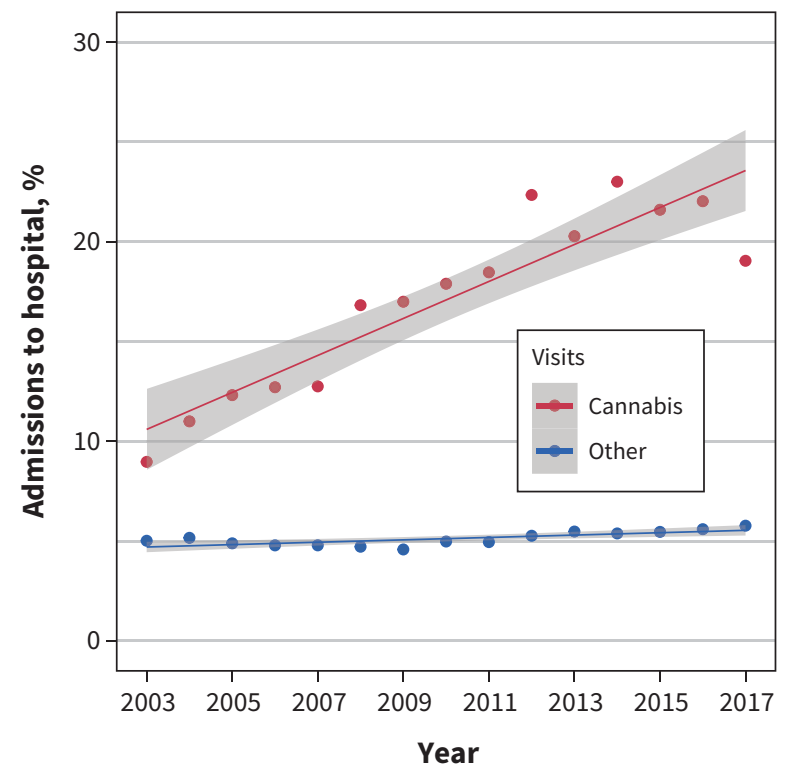

Figure 2: Trends in severity of emergency department visits and hospital admissions by visit type (cannabis related and other). (A) Severe CTAS scores by year and visit type, (B) hospital admissions by year and visit type. Note: CTAS = Canadian Triage and Acuity Scale. A severe CTAS score includes visits coded as urgent, emergent or resuscitation. Lines are ordinary least squares fits with 95\% confidence intervals (shaded areas).

\section{Interpretation}

In 2017, 4612 Ontario youths aged 10-24 years had emergency department visits for cannabis exposure, nearly 5 times the number in 2003. Although this was a small absolute increase in visit rates, from $0.1 \%$ to $0.5 \%$ of all visits, the increase in rates of emergency department visits for cannabis exposure accelerated over time, and the rapid increase raises concern about the impact of cannabis on youth.

Cannabis-related emergency department visits were more common among males, although rates increased for both sexes. Cannabis-related visits were more common and increased more quickly among youth aged 14-18 and 19-24 years than among those aged 10-13 years. Similar increases in cannabis-related visits among youths have been reported in other jurisdictions, including the United States, ${ }^{12,32}$ Colorado, ${ }^{33}$ Washington state ${ }^{34}$ and France. ${ }^{35}$

In the current study, cannabis-related visits were more severe at presentation than visits for other conditions, and the proportion of cannabis-related visits triaged as severe increased between 2003 and 2017. The triaged severity of non-cannabisrelated visits also increased during this period, so it is conceivable that use of the CTAS has changed over time. However, a patient with a cannabis-related visit was twice as likely to be admitted to hospital in 2017 than in 2003, and in 2017 they were more than 3 times as likely to be admitted to hospital than those with non-cannabis-related visits. On balance, the data suggest that the severity of cannabis-related visits has increased, which is consistent with the increasing potency of cannabis-related preparations discussed below.

One possible explanation for the increase in cannabisrelated emergency department visits is an increase in cannabis use in the adolescent population. However, the Canadian Tobacco, Alcohol and Drugs Survey reported no increase from 2015 to 2017 in past-year cannabis use for youth aged 15 to 24 years. ${ }^{36}$ The Ontario Student Drug Use and Health Survey found substantial self-reported decreases in cannabis use among Ontario high school students, from $28.0 \%$ in 1999 to $19.0 \%$ in 2017.37

Emergency department visits could increase even when cannabis use in the general youth population decreased if use increased in a small but high-risk subset of the population. Many of these youths may have concurrent mental health problems, and emergency department visits for these problems have increased during the same period. ${ }^{10}$ However, it is unclear whether this increase is a result of increased prevalence of mental health disorders or increased help-seeking for these disorders. ${ }^{38}$ An alternative explanation is that as cannabis has become increasingly accepted for Canadian adults, cannabis surveillance has increased within emergency departments. If so, the increase in cannabis-related emergency department visits could reflect a greater propensity for clinicians to diagnose a visit as cannabis related.

Cannabis-related emergency department visits may also have increased because cannabis users are increasingly exposed to potent cannabis products or efficient modes of drug administration. Chandra and colleagues ${ }^{39}$ report that the tetrahydrocannabinol (THC) concentrations in cannabis preparations seized in the US nearly doubled from 2008 to 2017. Tetrahydrocannabinol concentrations in European samples likewise doubled from 2006 to $2016 ;{ }^{40}$ potency increases have also been reported by French police ${ }^{35}$ and 


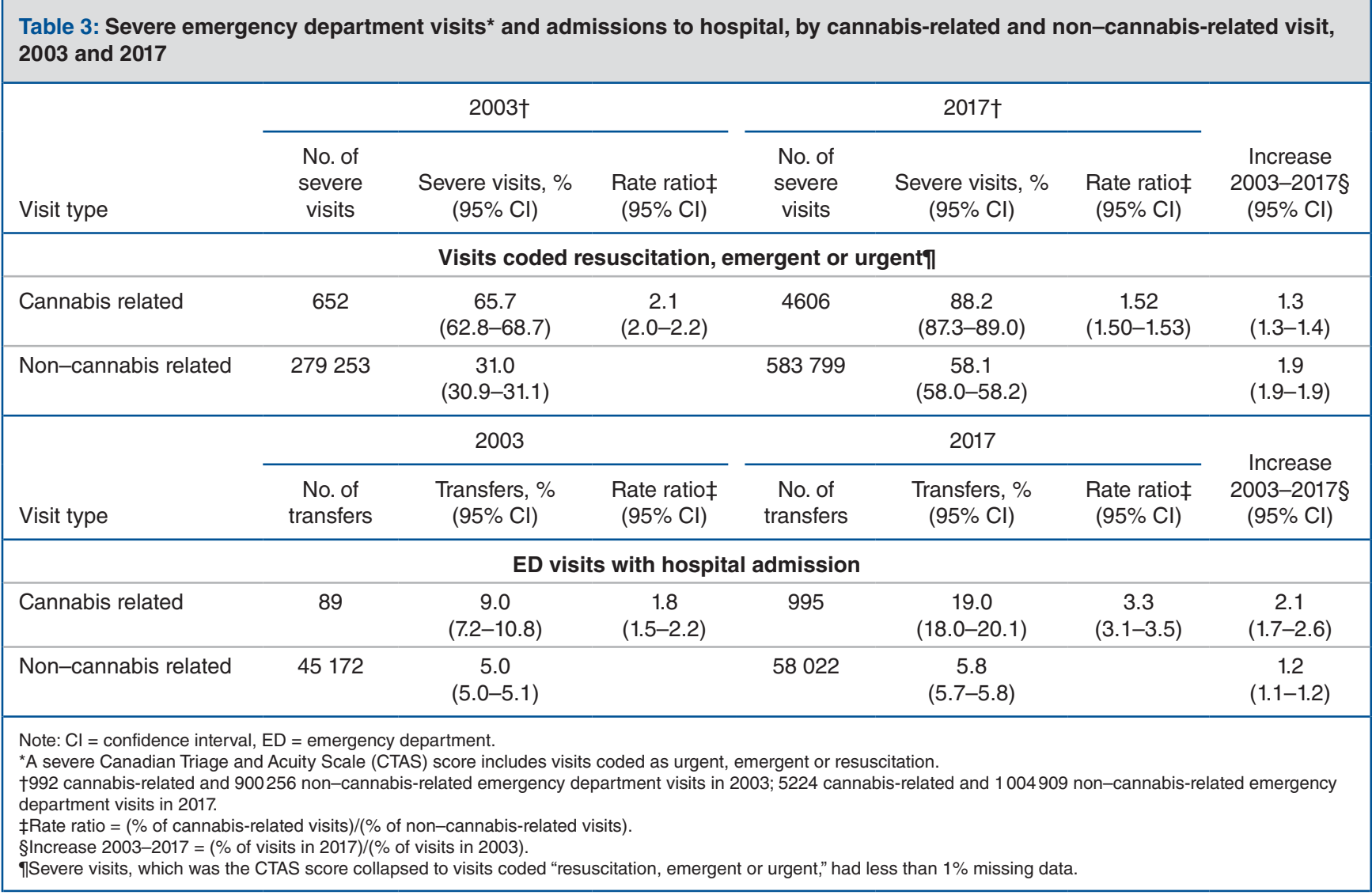

Dutch retailers. ${ }^{40}$ Synthetic cannabinoids are of particular concern; patients may present to the emergency department with agitation or somnolence, emesis, tachycardia and hypertension. ${ }^{41}$ Cannabis vaping can deliver high doses of THC and has been increasing among US adolescents. ${ }^{42-44}$ We speculate that potent preparations and modes of drug administration may also explain the increasing acuity of presentation noted in our study. ${ }^{45,46}$ The long-term effects of these novel products and consumption patterns are not currently known.

With more potent cannabis formulations and ingestion methods, youths may present to the emergency department in a way that is difficult to distinguish from a primary psychotic disorder. The agitation of acute paranoia would be scored higher on the CTAS (e.g., these individuals may require physical or chemical restraint). These patients may also require hospitalization if discriminating between cannabis toxicity and psychosis requires too much time for a typical emergency department visit, which may explain the increase in admission rates over time.

Awareness of cannabis-related emergency department visits is relevant in Canada after the Cannabis Act came into effect on Oct. 17, 2018, ${ }^{47}$ legalizing recreational use for people aged 18 years and older. Colorado's legalization was followed by increases in cannabis-related emergency department visits, calls to poison control centres and hospitalizations. ${ }^{48,49}$ This suggests that Canadian rates of cannabis-related emergency department visits may continue to rise. Because edible cannabis preparations are now available throughout Canada, vigilance is required concerning the exposure to cannabis among children.

We suggest that emergency department clinicians maintain a high index of suspicion for cannabis exposure in young people presenting with nonspecific somnolence or psychomotor agitation. Asking about possible cannabis exposure early in the clinical encounter may help avoid unnecessary diagnostic testing. Parents and youth should be counselled about the acute and chronic risks of cannabis exposure, including the possible effects on mental health and the safety of prolonged use or of products with high THC concentrations. ${ }^{5,6,25}$

\section{Limitations}

Our study was observational and used administrative data. Administrative records are subject to several forms of error, including inaccurate or incomplete documentation of problems by clinicians and errors in coding and abstraction of data from clinical records, so that health administrative data to identify substance use presentations has low sensitivity but high specificity. ICD-10 codes have not been validated for cannabis-related emergency department visits. Consequently, some of the visits are likely misclassified in our data, as has been found in a recent study of ICD-10 coding of opioid misuse. ${ }^{50}$ Therefore, our results likely underestimate the rates of cannabis-related emergency department visits. 
NACRS records lack information about the cannabis preparation, how the youth consumed the drug or whether the youth was a chronic user. They do not include standardized mental health assessment instruments. Given that NACRS records have limited information, our understanding of the presenting features, treatments and discharge planning for these patients is limited. Our data may also overstate the increase in cannabis visits if youths have become more likely to disclose use over time. Finally, our study uses data from a single Canadian province and may have limited generalizability.

\section{Conclusion}

Cannabis-related emergency department visits increased in Ontario from 2003 to 2017 among youths aged 14 to 24 years. Moreover, these visits were increasingly likely to be triaged as severe and to result in hospitalization. These trends describe an emerging public health problem. Research is needed to identify the causes of this increase and the health and social consequences of cannabis-related visits for these youths. Further studies of the complex and multifactorial predictors and causes of cannabis-related emergency department presentations will help guide preventive efforts. Youths with multiple emergency department visits related to substance use are of special concern. Future studies will be able to assess the effect of the legalization of cannabis on trends in emergency department visits. Research is also needed on the follow-up care patients receive after discharge from the emergency department or hospital after a cannabis-related visit.

\section{References}

1. Dines AM, Wood DM, Galicia M, et al. Presentations to the emergency department following cannabis use - a multi-centre case series from ten European countries. $\mathcal{F}$ Med Toxicol 2015;11:415-21.

2. Chen Y-C, Klig JE. Cannabis-related emergencies in children and teens. Curr Opin Pediatr 2019;31:291-6.

3. Richards JR, Smith NE, Moulin AK. Unintentional cannabis ingestion in children: a systematic review. F Pediatr 2017;190:142-52.

4. Onders B, Casavant MJ, Spiller HA, et al. Marijuana exposure among children younger than six years in the United States. Clin Pediatr (Phila) 2016;55:428-36.

5. Broyd SJ, van Hell HH, Beale C, et al. Acute and chronic effects of cannabinoids on human cognition: a systematic review. Biol Psychiatry 2016;79:557-67.

6. Wilkinson ST, Radhakrishnan R, D'Souza DC. Impact of cannabis use on the development of psychotic disorders. Curr Addict Rep 2014;1:115-28.

7. Bashqoy F, Heizer JW, Reiter PD, et al. Increased testing and health care costs for pediatric cannabis exposures. Pediatr Emerg Care 2019 Apr. 12 [Epub ahead of print]. doi: 10.1097/PEC.0000000000001811.

8. High school and youth trends in drug use monitoring the future survey. National Institute on Drug Abuse; 2020. Available: https://www.drugabuse. gov/drug-topics/trends-statistics/monitoring-future (accessed 2022 Jan. 21.)

9. Becker JB, Hu M. Sex differences in drug abuse. Front Neuroendocrinol 2008; 29:36-47.

10. Gardner W, Pajer K, Cloutier P, et al. Changing rates of self-harm and mental disorders by sex in youths presenting to Ontario emergency departments: repeated cross-sectional Study. Can 7 Psychiatry 2019;64:789-97.

11. Shen JJ, Shan G, Kim PC, et al. Trends and related factors of cannabisassociated emergency department visits in the United States: 2006-2014. 7 Addict Med 2019;13:193-200.

12. Zhu H, Wu L-T. Trends and correlates of cannabis-involved emergency department visits: 2004 to 2011. 7 Addict Med 2016;10:429-36.

13. International Classification of Diseases, Tenth Revision, Clinical Modification (ICD10-CM). Geneva: World Health Organization; 1996.

14. Murray MJ. The Canadian Triage and Acuity Scale: a Canadian perspective on emergency department triage. Emerg Med (Fremantle) 2003;15:6-10.

15. Gravel J, Manzano S, Arsenault M. Validity of the Canadian Paediatric Triage and Acuity Scale in a tertiary care hospital. CFEM 2009;11:23-8.
16. Bergeron S, Gouin S, Bailey B, et al. Agreement among pediatric health care professionals with the pediatric Canadian triage and acuity scale guidelines. Pediatr Emerg Care 2004;20:514-8.

17. Tips for coders: selecting the external cause code for a poisoning by drugs, medicaments and biological substances. Ottawa: Canadian Institute for Health Information; 2018.

18. F10-F19: Mental and behavioural disorders due to psychoactive substance use. In: The ICD-10 Classification of Mental and Behavioural Disorders: Clinical descriptions and diagnostic guidelines. Geneva: World Health Organization; 1993.

19. Green CA, Perrin NA, Janoff SL, et al. Assessing the accuracy of opioid overdose and poisoning codes in diagnostic information from electronic health records, claims data, and death records. Pharmacoepidemiol Drug Saf 2017;26:509-17.

20. Cherpitel C, Bond J, Ye Y, et al. Clinical assessment compared with breathalyser readings in the emergency room: concordance of ICD-10 Y90 and Y91 codes. Emerg Med 7 2005;22:689-95.

21. Gibson D, Richards H, Chapman A. The national ambulatory care reporting system: factors that affect the quality of its emergency data. International Fournal of Information Quality 2008;2:97-114.

22. DeYoung K, Chen Y, Beum R, et al. Validation of a syndromic case definition for detecting emergency department visits potentially related to marijuana. Public Health Rep 2017;132:471-9.

23. Claudet I, Mouvier S, Labadie M, et al.; Marie-Jeanne Study Group. Unintentional cannabis intoxication in toddlers. Pediatrics 2017;140:e20170017.

24. Claudet I, Le Breton M, Bréhin C, et al. A 10-year review of cannabis exposure in children under 3 years of age: Do we need a more global approach? Eur 7 Pediatr 2017;176:553-6.

25. Monte AA, Shelton SK, Mills E, et al. Acute illness associated with cannabis use, by route of exposure an observational study. Ann Intern Med 2019;170:531-7.

26. Noel GN, Maghoo AM, Franke FF, et al. Increase in emergency department visits related to cannabis reported using syndromic surveillance system. Eur $\mathcal{F}$ Public Health 2019;29:621-5.

27. Pélissier F, Claudet I, Pélissier-Alicot A-L, et al. Parental cannabis abuse and accidental intoxications in children prevention by detecting neglectful situations and at-risk families. Pediatr Emerg Care 2014;30:862-6.

28. Wang GS, Le Lait MC, Deakyne SJ, et al. Unintentional pediatric exposures to marijuana in Colorado, 2009-2015. FAMA Pediatr 2016;170:e160971.

29. Kim HM, Smith EG, Stano CM, et al. Validation of key behaviourally based mental health diagnoses in administrative data: suicide attempt, alcohol abuse, illicit drug abuse and tobacco use. BMC Health Serv Res 2012;12:18.

30. Ontario Ministry of Health and Long Term Care. IntelliHealth. Queen's Printer for Ontario.

31. Kahn H, Sempos C. Statistical methods in epidemiology. New York: Oxford University Press; 1989.

32. Shen JJ, Shan G, Kim PC, et al. Trends and related factors of cannabisassociated emergency department visits in the United States: 2006-2014. 7 Addict Med 2019;13:193-200.

33. Wang GS, Davies SD, Halmo LS, et al. Impact of marijuana legalization in Colorado on adolescent emergency and urgent care visits. 7 Adolesc Health 2018;63:239-41.

34. Thomas AA, von Derau K, Bradford MC, et al. Unintentional pediatric marijuana exposures prior to and after legalization and commercial availability of recreational marijuana in Washington State. F Emerg Med 2019;56:398-404.

35. Dujourdy L, Besacier F. A study of cannabis potency in France over a 25 years period (1992-2016). Forensic Sci Int 2017;272:72-80.

36. Canadian Tobacco, Alcohol and Drugs Survey (CTADS): summary of results for 2017. Ottawa: Health Canada; modified 2021 Aug. 12.

37. Boak A, Hamilton HA, Adlaf EM, et al. Drug use among Ontario students, 1977-2017: detailed findings from the Ontario Student Drug Use and Health Survey (OSDUHS). CAMH Research Document Series no 46. Toronto: Centre for Addiction and Mental Health; 2017.

38. Chiu M, Amartey A, Wang X, et al. Trends in objectively measured and perceived mental health and use of mental health services: a population-based study in Ontario, 2002-2014. CMA7 2020;192:E329-37.

39. Chandra S, Radwan MM, Majumdar CG, et al. New trends in cannabis potency in USA and Europe during the last decade (2008-2017). Eur Arch Psychiatry Clin Neurosci 2019;269:5-15.

40. Freeman TP, Groshkova T, Cunningham A, et al. Increasing potency and price of cannabis in Europe, 2006-16. Addiction 2019;114:1015-23.

41. Zaurova M, Hoffman RS, Vlahov D, et al. Clinical effects of synthetic cannabinoid receptor agonists compared with marijuana in emergency department patients with acute drug overdose. 7 Med Toxicol 2016;12:335-40.

42. Palamar JJ, Martins SS, Su MK, et al. Self-reported use of novel psychoactive substances in a US nationally representative survey: prevalence, correlates, and a call for new survey methods to prevent underreporting. Drug Alcobol Depend 2015;156:112-9. 
43. Miech R, Johnston L, Malley $\mathrm{O}$, et al. Adolescent vaping and nicotine use in 2017-2018: U.S. national estimates. N Engl f Med 2019;380:192-3.

44. Dai H. Self-reported marijuana use in electronic cigarettes among US youth, 2017 to 2018. FAMA 2020;323:473-4.

45. ElSohly MA, Mehmedic Z, Foster S, et al. Changes in cannabis potency over the last two decades (1995-2014): analysis of current data in the United States. Biol Psychiatry 2016;79:613-9.

46. Sevigny EL, Pacula RL, Heaton P. The effects of medical marijuana laws on potency. Int 7 Drug Policy 2014;25:308-19.

47. Cannabis legalization and regulation. Ottawa: Department of Justice; modified 2021 July 7.

48. Wang GS, Hall K, Vigil D, et al. Marijuana and acute health care contacts in Colorado. Prev Med 2017;104:24-30.

49. Calcaterra SL, Hopfer CJ, Keniston A, et al. Changes in healthcare encounter rates possibly related to cannabis or alcohol following legalization of recreational marijuana in a safety-net hospital: an interrupted time series analysis. F Addict Med 2019;13:201-8.

50. Lagisetty P, Garpestad C, Larkin A, et al. Identifying individuals with opioid use disorder: validity of International Classification of Diseases diagnostic codes for opioid use, dependence and abuse. Drug Alcohol Depend 2021;221: 108583 .

Affiliations: Department of Pediatrics (Bechard, Zemek, Bhatt), University of Ottawa; Children's Hospital of Eastern Ontario Research Institute (Cloutier, Salamatmanesh, Zemek, Bhatt, Gardner); ICES uOttawa (Lima); Department of Psychiatry (Suntharalingam, Gardner), University of Ottawa, Ottawa, Ont.; The Centre for Addiction and Mental Health (Kurdyak); Department of Psychiatry (Kurdyak), University of Toronto, Toronto, Ont.; Public Health Agency of Canada (Baker); School of Epidemiology and Public Health (Gardner), University of Ottawa, Ottawa, Ont.

Contributors: Melanie Bechard, Roger Zemek, Mina Salamatmanesh, Maala Bhatt, Sinthuja Suntharalingam, Paul Kurdyak and Melissa Baker contributed to the conception or design of the work, analysis and interpretation of the data, to the drafting of the manuscript, and the revision of critical content. Isac Lima contributed to the analysis and interpretation of the data, to the drafting of the manuscript, and the revision of critical content. Paula Cloutier and William Gardner contributed to the conception or design of the work, acquisition of the data, analysis and interpretation of the data, to the drafting of the manuscript, the revision of critical content, and to securing the funding for the research. Isac Lima had full access to all the data in the study and carried out the preliminary analyses to calculate the annual emergency department visit counts and demographic statistics analyzed in this article. William Gardner carried out the analyses of the visit counts. All authors approved the final version of the manuscript and agree to be accountable for all aspects of the work in ensuring that questions related to the accuracy or integrity of any part of the work are appropriately investigated and resolved.

Funding: This research was funded by a contract from the Public Health Agency of Canada (PHAC). The researchers are independent from the funder, with the exception of Melissa Baker, who is employed by PHAC. This study was also supported by ICES, which is funded by an annual grant from the Ontario Ministry of Health. ICES reviewed the plan for creating the data set and analyzing the data. Other than author Isac Lima, who was then an ICES employee, ICES played no role in the management, analysis and interpretation of the data, or the preparation or review of the manuscript. Author Paul Kurdyak was the ICES scientist on this project, and he reviewed the manuscript to ensure that it complied with ICES and provincial data privacy laws and regulations. Otherwise, the funders had no role in the design and conduct of the study; the collection, management, analysis and interpretation of the data; the preparation, review or approval of the manuscript; or the decision to submit the manuscript for publication.

Content licence: This is an Open Access article distributed in accordance with the terms of the Creative Commons Attribution (CC BY-NC-ND 4.0) licence, which permits use, distribution and reproduction in any medium, provided that the original publication is properly cited, the use is noncommercial (i.e., research or educational use), and no modifications or adaptations are made. See: https://creativecommons.org/licenses/ by-nc-nd/4.0/

Data sharing: The data set from this study is held securely in coded form at ICES. While data sharing agreements prohibit ICES from making the data set publicly available, access may be granted to those who meet prespecified criteria for confidential access, available at https://www.ices. on.ca/DAS. The full data set creation plan and underlying analytic code are available from the authors on request, understanding that the computer programs may rely on coding templates or macros that are unique to ICES and are therefore either inaccessible or may require modification. $\mathrm{R}$ code is available from the corresponding author.

Supplemental information: For reviewer comments and the original submission of this manuscript, please see www.cmajopen.ca/content/10/1/ E100/suppl/DC1. 